\title{
Pigmented villonodular synovitis of the temporomandibular joint: A case study
}

\author{
Stephanie Tan*, Phillip Marsh and Alistair Reid \\ Princess Alexandra Hospital, Brisbane, Queensland, Australia
}

\begin{abstract}
Background: Pigmented villonodular synovitis (PVNS) is a benign but locally aggressive proliferative disorder, commonly arising from the synovium of long bone joints, tendon sheaths and bursae.

PVNS is rarely found in the temporomandibular joint (TMJ), with around 52 reported cases in the current English literature. It is most commonly found in the knee joint, followed by the hip, ankle, small joints of the hands and feet, wrist, shoulder and elbow.

Case study: This case report describes a 37 year old Cantonese lady who presented with a progressively enlarging mass at her right TMJ. Initial imaging and biopsies initially favoured a primary salivary gland neoplasm, with recommendations for surgical excision. Subsequent ultrasound core guided biopsy showed appearances consistent with a diffuse giant cell tumour (pigmented villonodular tenosynovitis). The patient underwent a superficial parotidectomy with clear surgical margins and no evidence of neoplasia in frozen sections.

Conclusions: This case highlights the challenges involved in the diagnosis and management of this rare condition, showing how its clinical presentation can mimic a parotid mass. Radiological and histological investigations can often give conflicting results. Long term follow up is required given the high chance of local recurrence and potential for aggressive change.
\end{abstract}

\section{Introduction}

Pigmented villonodular synovitis (PVNS) is a benign but locally aggressive proliferative disorder, commonly arising from the synovium of long bone joints, tendon sheaths and bursae.

It belongs to a family of synovial proliferative lesions, with two variants depending on the area involved: diffuse type tenosynovial giant cell tumour (affecting entire synovial joint membrane or bursa), often used interchangeably with PVNS, and the localised form (affecting only a portion of joint lining or tendon sheath). The diffuse form is more prevalent and usually occurs as an intramonoarticular arthropathy or rarely as an extra articular bursitis [1].

PVNS is most commonly found in the knee joint, followed by the hip, ankle, small joints of the hands and feet, wrist, shoulder and elbow. It has an annual incidence of 1.8 per million population, most commonly affecting those in the third to fifth decade, however no gender predilection exists [1]. PVNS rarely presents in the temporomandibular joint (TMJ), with only around 52 cases of PVNS affecting the TMJ reported in the English literature to date, a third of which exhibit intracranial involvement[2]. Lapayoker et al. is believed to have described the first report of PVNS in the TMJ in 1973 [2].

\section{Case report}

A 37 year old Cantonese lady was referred by her GP to the Princess Alexandra Hospital Oral \& Maxillofacial outpatient clinic with a progressively enlarging painful mass at her right TMJ, initially noticed three years ago. There was no history of trauma, significant medical history or medication use. Previous orthopantomogram (OPG) and computed tomography (CT) scan of the TMJ in August 2010 showed normal joint spaces and symmetry with no evidence of joint subluxation or displacement and normal appearing bony structures.

On initial examination in February 2012, the patient was noted to have a $1.5 \times 1.5 \mathrm{~cm}$ right preauricular mass which appeared fixed to the root of the zygoma. The lump was tender to palpation and worse on full mouth opening, but non tender on chewing. There was mandibular deviation to the right hand side on opening, with a palpable right TMJ. Pain was localised andnon-radiatingbut didnot interfere with daily functioning. She did not have any signs of facial nerve palsy or trismus and there were no other palpable abnormalities in the neck. She did not report any hearing loss.

The patient underwent magnetic resonance imaging (MRI) of the TMJ, which showed an irregularity of the articular cartilage with synovial thickening. This was confirmed with an ultrasound (US) of the soft tissues.

Two separate fine needle aspirate biopsies (FNAB) of the right parotid gland showed features suggesting a primary salivary gland neoplasm with recommendations for excision. A repeat MRI and CT scan of the neck showed a poorly defined ring enhancing mass measuring $18 \times 16 \times 11 \mathrm{~mm}$ in the superior pole of the right parotid gland

Correspondence to: Stephanie Tan, 237 Ipswich Road, Woolloongabba, Princess Alexandra Hospital, Queensland, 4006, Australia, Tel: +61438817733; E-mail: stephtan88@gmail.com

Key words: giant cell tumour; synovial tumour; temporomandibular joint; salivary gland neoplasm

Received: May 20, 2015; Accepted: June 17, 2015; Published: June 22, 2015 


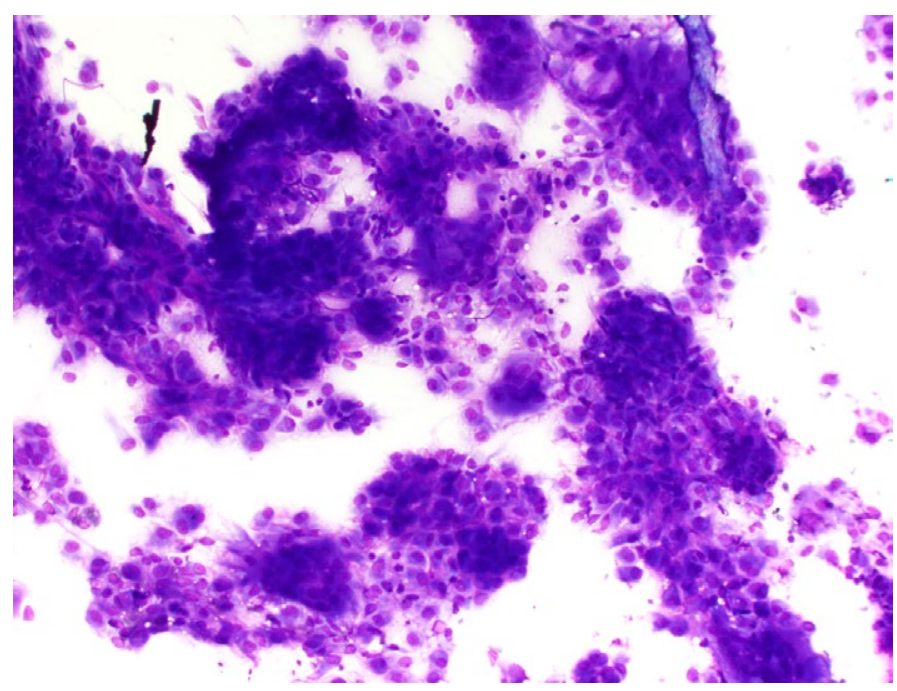

Figure 1. FNA Biopsy of right pre auricular mass showing epithelial cells, scattered pigmented laden macrophages and giant cells, favouring a primary salivary gland neoplasm. Note both FNAB reports recommended excision for accurate diagnosis.

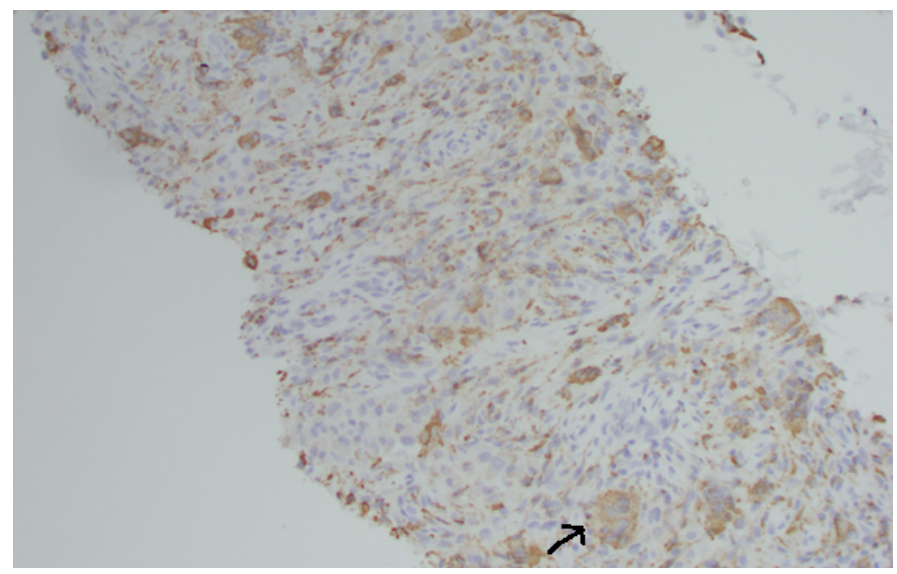

Figure 2. Core Biopsy showing positive staining for macrophage associated antigen CD68 and hemosiderin containing cells.

lateral to the TMJ, with no bony erosion or facial nerve involvement. Both the MRI and CT supported the histologically reported salivary gland neoplasm.

The patient was subsequently referred to the Ear, Nose and Throat (ENT) department for ongoing management, including discussion at the head and neck multidisciplinary meeting, with the provisional diagnosis of a T1N0M0 primary salivary gland malignancy.

A US core biopsy was arranged to confirm the diagnosis. This was consistent with diffuse type giant cell tumour (pigmented villonodular tenosynovitis).

Based on the inconsistent histology from the 2 FNAB and core biopsy samples, after further discussion, a combined ENT and Maxillofacial approach was decided, with the patient undergoing a right superficial parotidectomy and excision of tumour of the upper pole of the right parotid.

The frontal branch of the facial nerve was sacrificed due to its course through the tumour. The tumour was otherwise completely excised successfully.
Histology revealed giant cell tumour infiltrating the right parotid and surrounding lymph nodes, clear of margins and no perineural invasion. There was no evidence of neoplasia in frozen section of the deep margin at the time of excision, confirming clear surgical margins.

The patient was most recently seen again in both ENT and Maxillofacial outpatient clinic one year since surgery and despite frontal branch weakness, was otherwise healing well.

She will continue to be reviewed at three monthly intervals over the next 2-3 years, with yearly review indefinitely.

\section{Discussion}

TMJ tumours are relatively uncommon, and are often diagnosed late due to their nonspecific symptoms which can be challenging to interpret. Tumours can arise in the TMJ, or in secondarily involved surrounding tissues.

Some confusion may arise regarding the naming and classification of such tumours. The World Health Organisation (WHO) currently

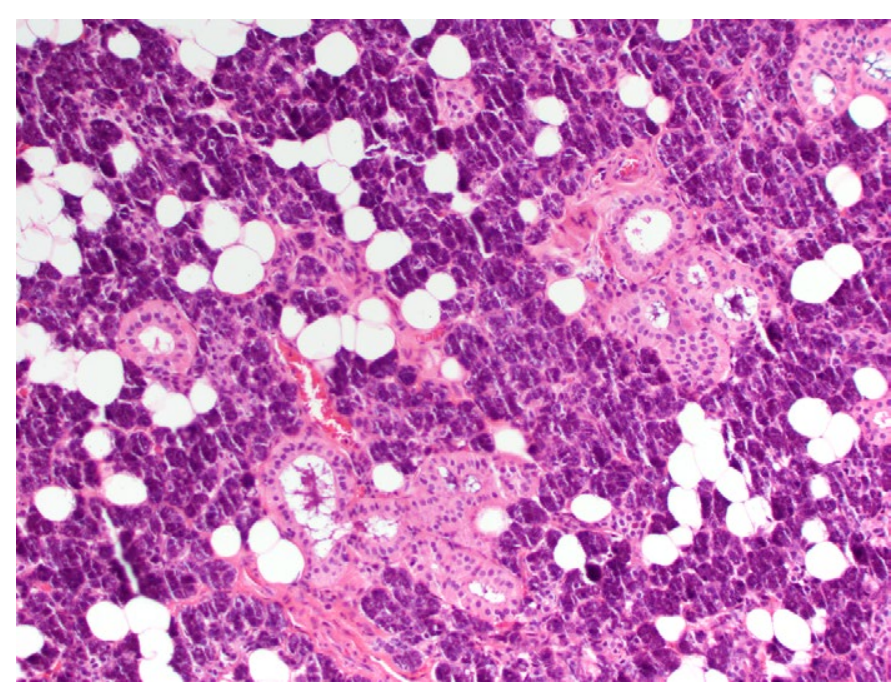

Figure 3. Normal parotid gland. (Note acinar cells in grape like bunches and mixed adipose tissue).

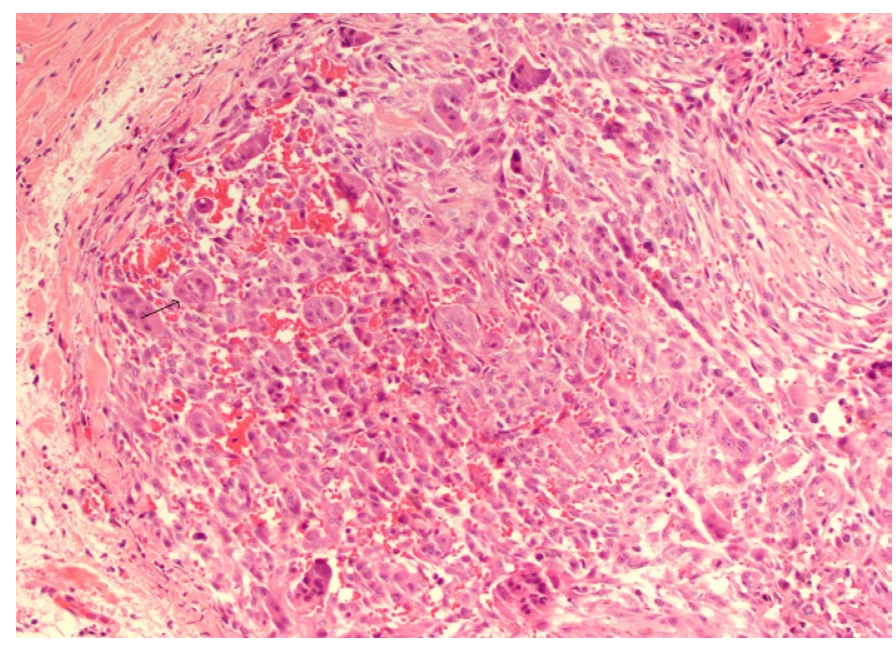

Figure 4. Frozen section right parotid mass showing mononuclear and multinucleate osteoclastic- type giant cells with focal hemosiderin deposition. 


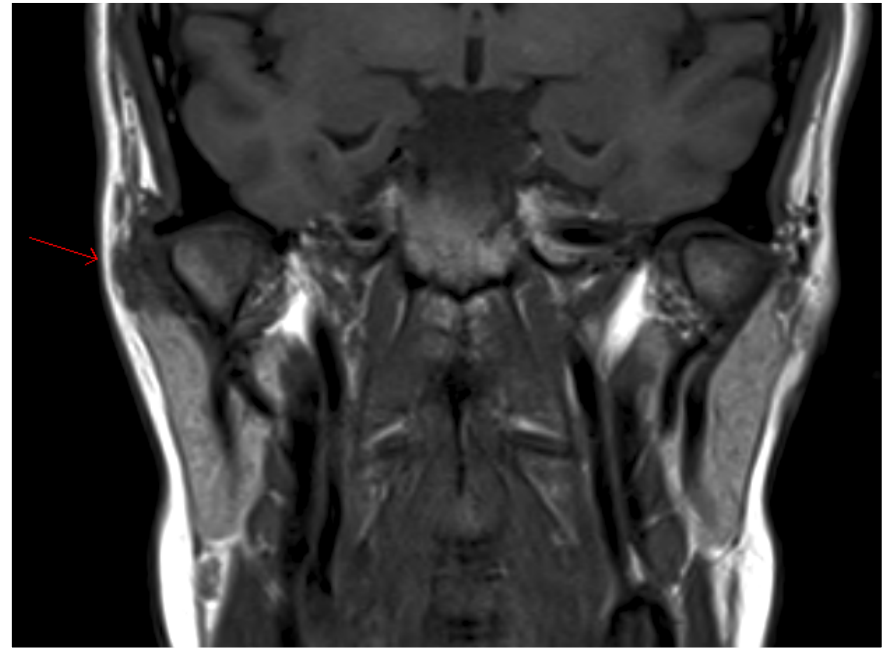

Figure 5. Coronal T1 weighted MRI showing lesion.

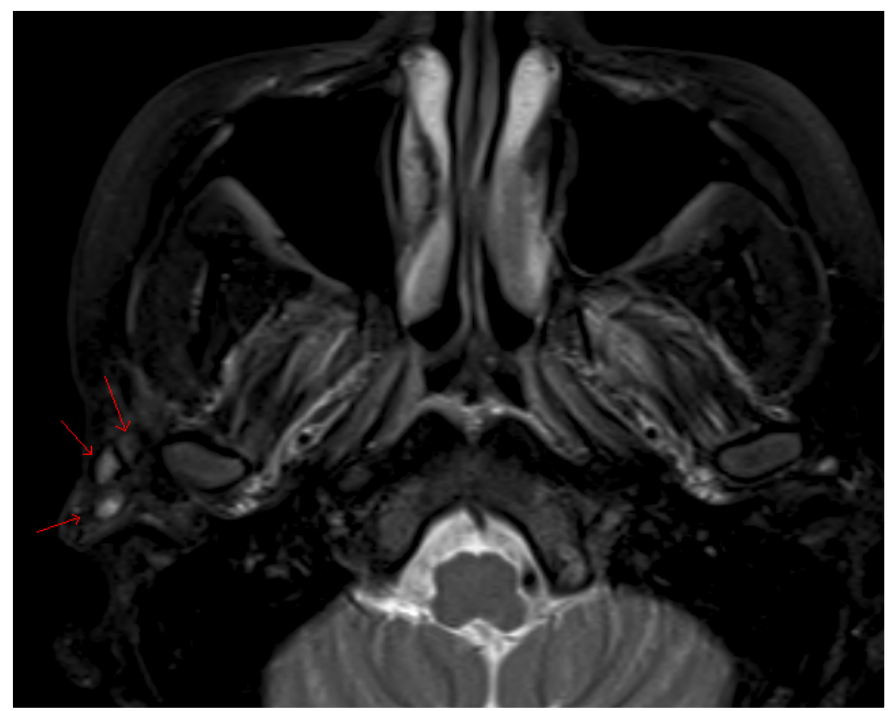

Figure 6. Axial T2 weighted MRI showing lesion.

classifies giant cell tumours of the tendon sheath (GCTTS) into subtypes according to site (intra or extra articular) and growth pattern (diffuse or localised) [3]. Localised GCTTS commonly affects the fingers, and involves only part of the synovium. Diffuse GCTTS has prevalence for the knee and hip joints of younger patients and involves the whole synovial membrane. Although the term diffuse type GCTTS is considered synonymous with PVNS, according to the WHO, the term PVNS is often referred to as including both the local and diffuse subtype, with intra or extra articular variants. However it is important to distinguish between the diffuse and localised subtype, as the diffuse form is more aggressive in nature and is associated with a poorer prognosis [2,3].

The cause and pathogenesis of PVNS remain unclear, however several theories have been suggested, including altered lipid metabolism, neoplasm, chronic, reactive inflammation of the synovium, trauma and local haemorrhage [4-6].

In particular, the continuous growth and aggressive behaviour exhibited by PVNS is characteristic of a true neoplasm. Reports have described trisomy of chromosomes 5 and 7, and recurrent structural abnormalities on the short arm of chromosome 1 (1p11-13) where the colony - stimulating factor 1 is located, on both localised and diffuse forms of PVNS [7]. These findings may suggest a neoplastic origin and have a role in the haemorrhagic tendency and histiogenesis of these lesions [8-11].

At present, around 52 cases of PVNS in the TMJ have been reported in the English literature [2].Of these, 25 were male, 26 female and 1 not specified. Age ranged from 10-78 years old with the mean age 44 years.

Common symptoms of PVNS of the TMJ include altered hearing, otalagia, progressive preauricular mass or swelling, pain, malocclusion, paraesthesia and TMJ symptoms such as clicking or trismus. These have all been described in previous cases to varying degrees.

Macroscopically, PVNS appears dark to yellow-brown in colour, with increased synovial thickening and a nodular and villous texture, often likened to a sponge. In some cases, loss of the typical villous feature is common, possible due to the predominantly diffuse growth pattern [3].

Microscopically, the synovium contains finger-like or rounded masses of vascularised fibrous stroma covered by hyperplastic synovial lining cells. Many cellular types are found including small and large mononuclear cells, osteoclast like multinucleated giant cells and xanthomatous macrophages.

Cleft like spaces and hyaline nodular formation can be found in the fibrous stroma, mimicking osteoid material, especially in the extra articular areas [12]. Plump spindle cells with multinucleated giant cells and foam macrophages containing lipid are present, accounting for the yellow colour. The brown colour is due to hemosiderin deposits in the stroma, cytoplasm of macrophages and synovial lining cells [13]. Staining methods for iron such as Perl's Prussian blue are used to identify these deposits.

The mononuclear histiocytes show positive immunoreactivity for CD68 and negative for S100, thus differentiating it from chondroblastoma cells, which are positive for S100 [14]. Primary parotid salivary gland tumours contain osteoclast- like giant cells similar to those seen in PVNS [15]. However these parotid tumours are usually high grade, and FNA of the lesions show cells with conspicuous atypia and malignant features. Generally immunohistochemistry is not essential for diagnosis of PVNS, but in certain cases such as this, can help to rule out other possible diagnoses.

Due to its aggressive nature and high recurrence rate, it is important to differentiate PVNS from other TMJ pathologies for early diagnosis and complete excision. The presentation of a preauricular swelling has a number of differential diagnoses, including synovial sarcoma, malignant synovioma (presence of amorphous calcification) and synovial chondromatosis (presence of small cartilaginous or ossific bodies) [5]. In $20 \%$ of cases, the preauricular swelling is misdiagnosed as a parotid mass [5] as seen in this case, which was reported as a primary salivary gland tumour.

Other differential diagnoses for lesions affecting the synovium and adjacent structures include: rheumatoid arthritis, gout, tophaceous pseudogout, tuberculosis, synovial osteochondromatosis, haemophilic arthropathy, amyloid arthropathy, chondroma, osteochondroma, synovial haemangioma, chronic osteomyelitis, serous otitis media, central giant cell lesion, sarcoma and metastasis [16-19].

Although malignant neoplasms are rare in the TMJ region, 
preauricular swellings are more commonly associated with salivary and cutaneous malignancies, including adenoid cystic carcinoma, mucoepidermoid carcinoma, malignant lymphoma, melanoma, squamous cell carcinoma, chondrosarcoma, synovial sarcoma, osteosarcoma and fibrosarcoma [20-22].

Metastases to the TMJ are rare, although there have been reports of metastases from primary cancers such as breast, lung, prostate, rectum, stomach, uterus and pancreas in the literature $[21,23,24]$.

Diagnosis involves a combination of clinical correlation with appropriate imaging and histopathology. Plain films are often nonspecific, but can occasionally show adjacent bone defects and sclerosis [25]. However as PVNS is of soft tissue origin, early lesions may not be detected on plain film [5]. CT is useful to show the extent of the lesion, as well as bony destruction. PVNS with high iron content typically shows a high density, non-calcifying soft tissue mass with erosion or extensive destruction of the condyle, temporal bone and infratemporal fossa on CT imaging [2]. MRI provides precise localisation of the mass, and its proximity to surrounding structures including bone and soft tissue involvement, and is a highly sensitive and specific method of establishing a diagnosis and aiding surgical planning. It shows a specific finding of low to intermediate signal in both T1- and T2 weighted images [26].

T-2 weighted images best demonstrate exaggerated MRI low signal intensity areas of PVNS, due to the high level of hemosiderin causing a paramagnetic effect from the reaction with iron. This creates an amplified signal dropout (signal void) in the regions of low signal seen on T1- and T2- weighted images. This marked signal void is known as "blooming artefact" or "susceptibility artefact" and is considered pathognomonic of PVNS [27]. High signal in T1- and T2- weighted images can also be attributed to the presence of lipids in xanthomatous macrophages and cystic areas respectively [28].

All imaging techniques were used in this patient's workup, in addition to FNA of the lesion. It should be noted that although FNA can be good for excluding diagnoses, especially malignancies, it is often less useful for exact categorisation of soft tissue tumours [29]. In these instances, an excisional biopsy is recommended.

Treatment of diffuse PVNS is aimed at preventing TMJ destruction and gradual loss of joint function. The majority of the literature recommends complete excision with wide surgical margins (synovium and involved bone). Incomplete surgical excision or diffuse involvement of surrounding structures ultimately leads to recurrence.

Radiotherapy has also been used in some aggressive diffuse PVNS cases for recurrence or salvage treatment [1]. Adjuvant radiotherapy is usually 2 months after surgery in 15-25 fractions with a dose range of $20-50$ Gy $[30,31]$.

Facial nerve paralysis is the most common complication after surgery for PVNS associated with TMJ [32], nevertheless near complete facial nerve recovery may be achieved with physical rehabilitation. In this case, the frontal branch of the facial nerve was sacrificed due to its course through the tumour. On follow-up, the patient was found to have subsequent facial weakness of the forehead, which was slowly improving with ongoing exercises.

Long term follow up is required for a minimum of 7 to 10 years with serial CT or MRI monitoring for signs of recurrence, which occurs primarily in the diffuse type in $8 \%$ to $46 \%$ of cases, usually from incomplete resection or spontaneously[5].

\section{Conclusion}

While rare, TMJ PVNS should be considered in patients presenting with preauricular swelling, trismus, hearing difficulties or altered sensation. Early referral to an oral and maxillofacial surgeon for clinical assessment, followed by radiologic and histopathologic investigations should be made, as patients have good long term results with early diagnosis and adequate resection. Various presentations of PVNS may to lead to frequent misdiagnosis, as seen in this case. This case highlights the challenges involved in the diagnosis and management of this rare condition, showing how its clinical presentation can mimic a parotid mass. Radiological and histological investigations can often give conflicting results, however are essential for the diagnosis of PVNS, which should be considered as a differential diagnosis for aggressive preauricular swellings. Long term follow up is required given the high chance of local recurrence and aggressive potential.

\section{Authorship and contributorship}

Stephanie Tan, Phillip Marsh, Alistair Reid.

\section{Acknowledgements}

The authors would like to thank Dr Alistair Reid (Oral and Maxillofacial consultant), Dr Scott Coman (Ear Nose and Throat consultant) and Dr Sam Boros (Anatomical Pathologist) at the Princess Alexandra Hospital for their support and contribution to this case study.

\section{Funding information}

This case report was not funded by any grants or financial support.

\section{Competing interests}

The authors do not have any known conflict of interest.

\section{References}

1. Bemporad JA, Chaloupka JC, Putman CM, Roth TC, Tarro J, et al. (1999) Pigmented villonodularsynovitis of the temporomandibular joint: diagnostic imaging and endovascular therapeutic embolization of a rare head and neck tumor. AJNR Am J Neuroradiol 20: 159-162. [Crossref]

2. Romañach MJ, Brasileiro BF, León JE, Alves DB, de Almeida OP, et al. (2011) Pigmented villonodularsynovitis of the temporomandibular joint: case report and review of the literature. Oral Surg Oral Med Oral Pathol Oral Radiol Endod 111: e17-28. [Crossref]

3. de St. Aubain-Somerhausen N, Dal CP (2002) Diffuse-type giant cell tumour. In: Fletcher CDM, Unni KK (Eds), World Health Organisation classification of tumours. Pathology and genetics of soft tissue and bone. Lyon: IARC Press: 112-114.

4. Granowitz SP, D'Antonio J, Mankin HL (1976) The pathogenesis and long-term end results of pigmented villonodularsynovitis. Clin Orthop Relat Res: 335-351. [Crossref]

5. Herman CR, Swift JQ, Schiffman EL (2009) Pigmented villonodularsynovitis of the temporomandibular joint with intracranial extension: a case and literature review. Int $J$ Oral Maxillofac Surg 38: 795-801. [Crossref]

6. Song MY, Heo MS, Lee SS, Choi SC, Park TW, et al. (1999) Diagnostic imaging of pigmented villonodularsynovitis of the temporomandibular joint associated with condylar expansion. Dentomaxillofac Radiol 28: 386-390. [Crossref]

7. Ohjimi Y, Iwasaki H, Ishiguro M, Kaneko Y, Tashiro H, et al. (1996) Short arm of chromosome 1 aberration recurrently found in pigmented villonodularsynovitis. Cancer Genet Cytogenet 90: 80-85. [Crossref]

8. Ofluoglu O (2006) Pigmented villonodularsynovitis. Orthop Clin North Am 37: 23-33. [Crossref]

9. Sciot R, Rosai J, Dal Cin P, de Wever I, Fletcher CD, et al. (1999) Analysis of 35 cases of localized and diffuse tenosynovial giant cell tumor: a report from the Chromosomes and Morphology (CHAMP) study group. Mod Pathol 12: 576-579. [Crossref] 
10. Dahlen A, Broberg K, Domanski HA, Toksvig-Larsen S, et al. (2001) Analysis of the distribution and frequency of trisomy 7 in vivo in synovia from patients with osteoarthritis and pigmented villonodularsynovitis. Cancer Genet Cytogenet 131: 1924. [Crossref]

11. Cupp JS, Miller MA, Montgomery KD, Nielsen TO, O'Connell JX, et al. (2007) Translocation and expression of CSF1 in pigmented villonodularsynovitis, tenosynovial giant cell tumor, rheumatoid arthritis and other reactive synovitides. Am J Surg Pathol 31: 970-976. [Crossref]

12. Somerhausen NS, Fletcher CD (2000) Diffuse-type giant cell tumor: clinicopathologic and immunohistochemical analysis of 50 cases with extraarticular disease. Am J Surg Pathol 24: 479-492. [Crossref]

13. Wong JJ, Phal PM, Wiesenfeld D (2012) Pigmented villonodularsynovitis of the temporomandibular joint: a radiologic diagnosis and case report. J Oral Maxillofac Surg 70: 126-134. [Crossref]

14. Kilpatrick SE, Parisien M, Bridge JA (2002) Chondroblastoma. In: Fletcher CDM, Unni KK, Mertens F (Eds) World Health Organisation Classification of Tumours. Pathology and Genetics of Tumours of Soft Tissue and Bone. International Agency for Research on Cancer Press: Lyon: 241-242.

15. Kadivar M, Nilipour Y, Sadeghipour A (2007) Osteoclast-like giant-cell tumor of the parotid with salivary duct carcinoma: case report and cytologic, histologic, and immunohistochemical findings. Ear Nose Throat J 86: 628-630. [Crossref]

16. Klenoff JR, Lowlicht RA, Lesnik T, Sasaki CT (2001) Mandibular and temporomandibular joint arthropathy in the differential diagnosis of the parotid mass. Laryngoscope 111: 2162-2165. [Crossref]

17. Stryjakowska KK, Martel M, Sasaki CT (2005) Pigmented villonodularsynovitis of the temporomandibular joint: differential diagnosis of the parotid mass. AurisNasus Larynx 32: 309-314. [Crossref]

18. Oda Y, Izumi T, Harimaya K, Segawa Y, Ishihara S, et al. (2007) Pigmented villonodularsynovitis with chondroid metaplasia, resembling chondroblastoma of the bone: a report of three cases. Mod Pathol 20: 545-551. [Crossref]

19. Kisnisci RS, Tuz HH, Gunhan O, Onder E (2001) Villonodularsynovitis of the temporomandibular joint: case report. J Oral Maxillofac Surg 59: 1482-1484. [Crossref]

20. Warner BF, Luna MA, Robert Newland T (2000) Temporomandibular joint neoplasms and pseudotumors. Adv Anat Pathol 7: 365-381. [Crossref]
21. Stojadinovic S, Reinert S, Wildförster U, Jundt G (1999) Destruction of the glenoid joint fossa by a tenosynovial giant-cell tumour of the skull base: a case report. Int J Oral Maxillofac Surg 28: 132-134. [Crossref]

22. Heo MS, An BM, Lee SS, Choi SC (2003) Use of advanced imaging modalities for the differential diagnosis of pathoses mimicking temporomandibular disorders. Oral Surg Oral Med Oral Pathol Oral Radiol Endod 96: 630-638. [Crossref]

23. DeBoom GW, Jensen JL, Siegel W, Bloom C (1985) Metastatic tumors of the mandibular condyle. Review of the literature and report of a case. Oral Surg Oral Med Oral Pathol 60: 512-516. [Crossref]

24. Shintaku WH, Venturin JS, Yepes JF (2009) Application of advanced imaging modalities for the diagnosis of metastatic adenocarcinoma of the lungs in the temporomandibular joint. Oral Surg Oral Med Oral Pathol Oral Radiol Endod 107: e37-41. [Crossref]

25. Mendenhall WM, Mendenhall CM, Reith JD, Scarborough MT, Gibbs CP, et al. (2006) Pigmented villonodularsynovitis. Am J Clin Oncol 29: 548-550. [Crossref]

26. Wan JM, Magarelli N, Peh WC, Guglielmi G, Shek TW (2010) Imaging of giant cell tumour of the tendon sheath. Radiol Med 115: 141-151. [Crossref]

27. Murphey MD, Rhee JH, Lewis RB, Fanburg-Smith JC, Flemming DJ, et al. (2008) Pigmented villonodularsynovitis: radiologic-pathologic correlation. Radiographics 28: 1493-1518. [Crossref]

28. Chen HS, Chang YL, Liang CW (2008) Radiology quiz case 2. Pigmented villonodularsynovitis of the temporomandibular joint. Arch Otolaryngol Head Neck Surg 134: 329, 331. [Crossref]

29. Dey P, Mallik MK, Gupta SK, Vasishta RK (2004) Role of fine needle aspiration cytology in the diagnosis of soft tissue tumours and tumour-like lesions. Cytopathology 15: 32-37. [Crossref]

30. O'Sullivan B, Cummings B, Catton C, Bell R, Davis A, et al. (1995) Outcome following radiation treatment for high-risk pigmented villonodularsynovitis. Int J Radiat Oncol Biol Phys 32: 777-786. [Crossref]

31. Horoschak M, Tran PT, Bachireddy P, West RB, Mohler D, et al. (2009) External beam radiation therapy enhances local control in pigmented villonodularsynovitis. Int $J$ Radiat Oncol Biol Phys75: 183-187. [Crossref]

32. Lee JH, Kim YY, Seo BM, Baek SH, Choi JY, et al. (2000) Extra-articular pigmented villonodularsynovitis of the temporomandibular joint: case report and review of the literature. Int J Oral Maxillofac Surg 29: 408-415. [Crossref]

Copyright: (C2015 Tan S. This is an open-access article distributed under the terms of the Creative Commons Attribution License, which permits unrestricted use, distribution, and reproduction in any medium, provided the original author and source are credited. 